\title{
SEISMIC DESIGN OF GRAVITY RETAINING WALLS
}

\author{
D. G. Elms * and R. Richards**
}

\begin{abstract}
SYNOPSIS
Starting from the Mononobe-okabe analysis, the seismic behaviour of gravity retaining walls is investigated. The importance of including wall inertia effects is demonstrated. The sensitivity of the results to changes in various parameters is explored: care must be taken in some ranges. For a moderately severe earthquake, it is shown that most walls will move, but that the movement is finite, and calculable.. An approximate expression is given for the expected displacement. From this, a design approach is developed in which the designer chooses an allowable displacement, uses it to compute a design acceleration coefficient, and then computes the wall mass required.
\end{abstract}

\section{SOIL FORCES ON THE WALI}

The most usual approach to the seismic design of a retaining wall is to assume the wall is acted on by a soil force given by the Mononobe-Okabe analysis. This analysis, described in detail by seed and Whitman' (4) is an extension of the coulomb sliding-wedge theory taking into account horizontal and vertical inertia forces acting on the soil. Where the backfill is not saturated, the active soil force $\mathrm{E}_{\mathrm{AE}}$ shown in Fig. 1 is given by the expression

$E_{A E}=\frac{\gamma \mathrm{H}^{2} g\left(1-k_{V}\right) \cos ^{2}(\phi-\theta-\beta)}{2 \cos \theta \cos ^{2} \beta \cos (\delta+\beta+\theta)\left[1+\sqrt{\left.\frac{\sin (\phi+\delta) \sin (\phi-\theta-i)}{\cos (\delta+\beta+\theta) \cos (i-\beta)}\right]^{2}}\right.}$

where

$\gamma=$ unit weight of soil

$\mathrm{H}=$ height of wall

$\phi \quad=$ angle of friction of soil

$\theta=\tan ^{-1}\left(\frac{\mathrm{k}_{\mathrm{h}}}{1-\mathrm{k}_{\mathrm{v}}}\right)$

$\mathrm{k}_{\mathrm{h}}=$ horizontal acceleration coefficient

$\mathrm{k}_{\mathrm{v}}=$ vertical acceleration coefficient

$g$ = gravitational acceleration

and the angles $i, \beta$ and $\delta$ are defined in Figure 1. Approximate solutions simpler in form are also given by seed and whitman.

If the wall is being pushed into the backfill, the maximum force that can result is the passive force

* Professor of Civil Engineering, University of Canterbury, Christchurch, N.Z.

** Associate Professor of Civil Engineering, University of Delaware, Newark, Del. 19711, U.S.A.

$$
E_{P E}=\frac{\gamma \mathrm{H}^{2} g\left(1-\mathrm{k}_{\mathrm{V}}\right) \cos ^{2}(\phi-\theta+\beta)}{2 \cos \theta \cos ^{2} \beta \cos (\delta-\beta+\theta)\left[1-\sqrt{\frac{\sin (\phi+\delta) \sin (\phi-\theta+i)}{\cos (\delta-\beta+\theta) \cos (i-\beta)}}\right]^{2}}
$$

Note that $\mathrm{E}_{\mathrm{AE}}$ and $\mathrm{E}_{\mathrm{PE}}$ approach each other as the seismic inertia angle $\theta$ increases, and become equal for a horizontal backfill when $\theta=\phi$.

Wood $(6,7)$ has shown that, provided the wall is flexible or is on flexible foundations so that it can move sufficiently for the soil strength to be mobilised, Eq. I is a good representation of the soil forces acting on the wall. He states, however, that for a rigid wall on a rigid foundation, the soil forces are higher and an approximate elasticity solution gives better results. The forces involved can be double those predicted by the Mononobe-okabe analysis.

The value of $h$, the height at which the resultant of the soil pressure acts on the wall, may be taken as $\mathrm{H} / 3$ for the static case with no earthquake effects involved. However, it becomes greater as earthquake effects increase. This has been shown by tests and by theoretical results derived by wood $(6,7)$, who found that the resultant of the dynamic pressure acted approximately at midheight. Seed and Whitman have suggested that $h$ could be obtained by assuming that the static component of the soil force (computed from Eq. I with $\theta=\mathrm{k}_{\mathrm{V}}=0$ ) acts at $\mathrm{H} / 3$ from the bottom of the wall, while the additional dynamic effect should be taken to act at a height of $0.6 \mathrm{H}$. For most purposes, it would be sufficient to assume $\mathrm{h}=\mathrm{H} / 2$, with a uniformly distributed pressure.

Although the Mononobe-Okabe expression for active thrust is easily evaluated for any particular geometry and friction angles, the significance of the various parameters is not obvious, nor is the approach convenient for preliminary design. The parametric study made by seed and Whitman demonstrates that both the angle of wall friction, $\delta$, and the vertical acceleration, $\mathrm{k}_{\mathrm{v}}$, are relatively 
insignificant and, moreover, their importance actually decreases as the earthquake intensity grows. On the other hand, as shown in Figures 2 and 3 , the active thrust is highly sensitive to both the backfill slope, $i$, and the friction angle of the soil, $\phi$. The design implications are clear. A backfill slope of even $10^{\circ}$ will, for $k_{h}=0.3$, almost double the additional dynamic component of thrust, or a decrease of $\phi$ of $5^{\circ}$ will give a $30 \%$ increase in the dynamic thrust for a horizontal backfill. A value of $\phi$ less than anticipated may be even more serious in that not only will the lateral thrust increase dramatically, but the shear strength and bearing capacity at the base will simultaneously decrease, giving a doubly severe situation.

One should also recognize the significance of the term $(\phi-\theta-i)$, the sine of which appears in the radical of the expression for $E_{A E}$ in Eq. 1. When this becomes negative no real solution is possible, corresponding physically to no possibility of equilibrium (as in the static case for slope stability when $i=\phi)$. When this term is zero the thrust is a maximum. Thus we have the limiting condition

$\phi-\theta-i \geq 0$

This may be thought of as limiting the feasible backfill angle $i$ such that

$i<\phi-\theta$

Thus for the static case for which $\theta=0$, the backfill angle, as expected, may not be greater than the angle of repose $\phi$; while for the practical case of a horizontal coefficient of acceleration $\mathrm{k}_{\mathrm{h}}=0.3$, no vertical acceleration and an angle of internal friction of $\phi=35^{\circ}$, then $\theta=17^{\circ}$ and the backfill angle must' be less than $i=18$.

Alternatively, Eq. 3 can be regarded as giving a limit to the acceleration that can be sustained, regardless of the nature of the retaining wall. For a horizontal backfill, this criterion becomes

$\theta \leq \phi$

or

$k_{h} \leq\left(1-k_{v}\right) \tan \phi$

The physical meaning of this is that the soil wedge angle becomes zero and a horizontal layer of soil simply could not transmit the shear forces produced by an acceleration level greater than $\theta=\phi$. It can be seen that for a vertical wall $(\beta=0)$ the active and passive pressures are equal and the soil forces simplify to

$\mathrm{E}_{\mathrm{AE}}=\mathrm{E}_{\mathrm{PE}}=\frac{\gamma \mathrm{H}^{2} \mathrm{q}}{2 \cos \theta \cos (\delta+\theta)}$

From Eq. 6 we can define a critical value of horizontal acceleration $\mathrm{k}_{\mathrm{h}}^{*}$ as

$k_{h}^{*}=\left(1-k_{v}\right) \tan \phi$

Values of the critical acceleration are plotted in Fig. 4, which gives an idea of the sensitivity of the various quantities involved. For instance, if $\phi=300$, then a vertical acceleration of $0.2 \mathrm{~g}$ results in $20 \%$ change in $k_{h}^{*}$.

\section{EFFECT OF WALL INERTIA}

Current procedures generally assume that the inertia forces due to the mass of the retaining wall itself may be neglected in considering the seismic behavior and seismic design of gravity retaining walls. This is clearly unconservative, and it is also unreasonable since it is actually the mass of the wall which provides most if not all of the resistance to movement.

The general free-body diagram for a retaining wall is shown in Fig. 1 , where $\mathrm{M}_{\mathrm{w}}$ is the mass of the wall and $\mathrm{R}$ is the reaction at the base with horizontal and vertical components $\mathrm{F}$ and N. From force equilibrium

$$
\begin{aligned}
& N=\left(1-k_{V}\right) M_{W} g+E_{A E} \sin (\delta+\beta) \\
& F=E_{A E} \cos (\delta+\beta)+k_{h} M_{W} g
\end{aligned}
$$

At sliding

$\mathrm{F}=\mathrm{N} \tan \phi_{\mathrm{b}}$

where $\phi_{b}$ is the friction angle at the base of the wall. Thus

$$
\begin{gathered}
E_{A E}\left[\cos (\delta+\beta)-\sin (\delta+\beta) \tan \phi_{b}\right] \\
=M_{W} g\left[\left(1-k_{v}\right) \tan \phi_{b}-k_{h}\right]
\end{gathered}
$$

and hence

$\mathrm{M}_{\mathrm{W}}=\frac{1}{\mathrm{~g}} \mathrm{C}_{\mathrm{IE}} \mathrm{E}_{\mathrm{AE}}$

where

$c_{I E}=\frac{\cos (\delta+\beta)-\sin (\delta+\beta) \tan \phi_{b}}{\left(1-\mathrm{k}_{\mathrm{v}}\right)\left(\tan \phi_{\mathrm{b}}-\tan \theta\right)}$

If the denominator of Eq. 14 becomes zero, a wall of infinite mass would be required to prevent motion. This condition will occur for a critical value $\mathrm{k}_{\mathrm{h}}^{*}$ of the coefficient of horizontal acceleration, where

$k_{h}^{*}=\left(1-k_{v}\right) \tan \phi_{b}$

The expression is independent of wall geometry and backfill slope. Comparing it with Eq. 3, Eq. 15 will govern only if $\phi_{\mathrm{b}}<\phi-i$. In many cases this condition will hold and, for various values of the parameters, it will be physically impossible to build a wall sufficiently massive to prevent motion. However, well before this limit is reached, economic considerations would restrict the size of the wall.

The relative importance of the two dynamic effects (i.e. the increased thrust on the wall due to inertia forces on the sliding wedge and the increase in driving force due to the inertia of the wall itself can be seen by normalizing them with regard to the static values. Thus we may define a soil thrust factor 


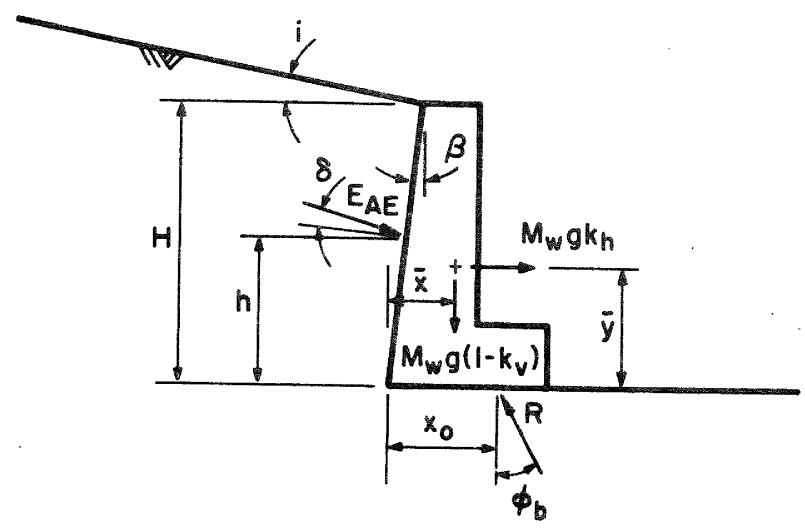

FIGURE 1: FREE BODY DIAGRAM OF GRAVITY RETAINING WALL
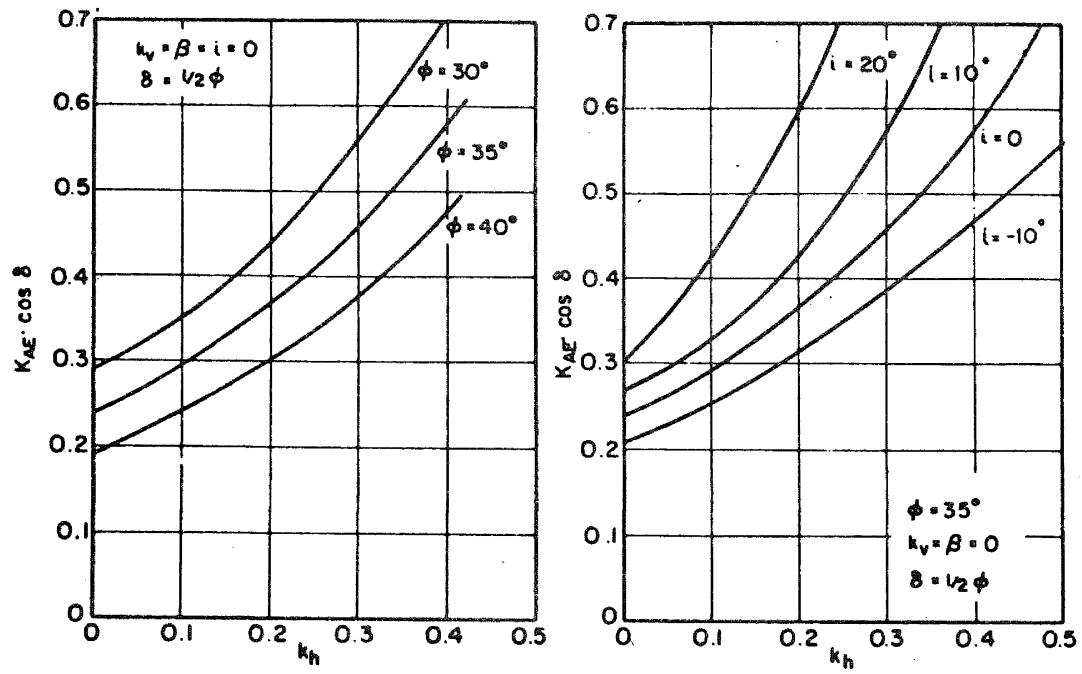

FIGURE 2: EFFECT OF SOIL FRICTION FIGURE 3: EFFECT OF BACKFILL SLOPE ANGLE ON SOIL THRUST ON SOIL THRUST

(AFTER SEED AND WHITMAN)

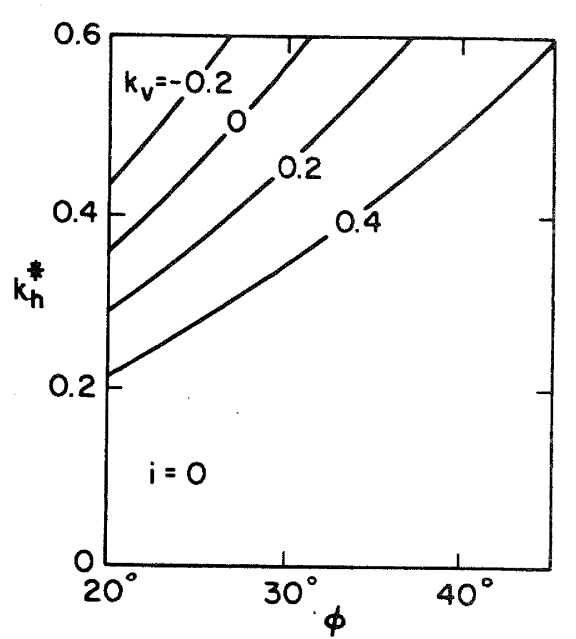

FIGURE 4: VALUES OF CRITICAL ACCELERATION

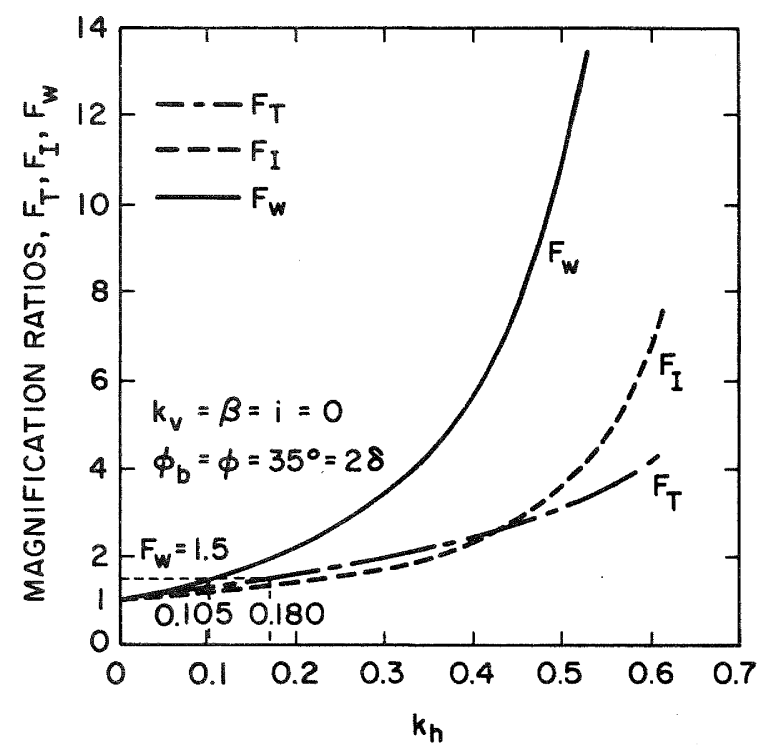

FIGURE 5: COMPARISON OF SOIL PRESSURE AND WALL INERTIA EFFECTS 
$F_{T}=\frac{E_{A E}}{E_{A}}$

and a wall inertia factor

$F_{I}=\frac{C_{I E}}{C_{I}}$

where $E_{A}$ and $C_{I}$ are static values of $E_{A E}$ and $C_{\text {IE }}$ for which the seismic inertia factors $k_{h}$ and $\mathrm{k}_{\mathrm{v}}$ are zero.

The product $F_{W}$ of the thrust and inertia factors is an amplification factor applied to the mass of the wall to allow for seismic effects on soil pressure and wall inertia. We shall call it the Seismic Amplification Factor (SAF): its value is given by the expression

$F_{W}=F_{T} F_{I}=\frac{M}{M}$

where $M$ is the mass of the wall required for equilibrium in the static case. As can be seen in Fig. 5, $F_{T}$ and $F_{T}$ are of the same order of magnitude for most values of $\mathrm{k}_{\mathrm{h}}$. Thus the wall inertia term cannot be neglected for the seismic design of gravity retaining walls or abutments. For a static design factor of safety of some value $F_{S}$ on the mass of the wall, then putting $\mathrm{F}_{\mathrm{S}}=\mathrm{F}_{\mathrm{W}}$, the horizontal acceleration at which sliding will take place can be read directly. If, for example, a wall were designed for $\mathrm{F}_{\mathrm{S}}=$ 1.5 , then for the parametric values specified in Fig. 5, motion would occur at $\mathrm{k}_{\mathrm{h}}=0.105$. Neglecting wall inertia, this value would be $\mathrm{k}_{\mathrm{h}}=0.18$. Thus it is most important to include wall inertia in the analysis.

\section{SENSITIVITY OF SEISMIC AMPLIFICATION FACTOR}

\section{TO PARAMETRIC CHANGES}

As the seismic amplification factor $F_{W}$ is made up of several terms each of which is a nonlinear function of the various parameters governing the behaviour of the wall, it is of interest to explore the sensitivity of $\mathrm{F}_{\mathrm{W}}$ to changes in these parameters.

Figures 6 and 7 show the variation of $F$ with changes in the value of the horizontal limiting acceleration coefficient $\mathrm{k}_{\mathrm{h}}$, for various values of vertical acceleration coefficient $\mathrm{k}_{\mathrm{v}}$ and soil friction angle $\phi$, assuming that $\phi_{\mathrm{b}}=\phi$. Clearly, $\mathrm{F}_{\mathrm{W}}$ increases steeply with $\mathrm{k}_{\mathrm{h}}$ : if $\mathrm{k}_{\mathrm{v}}=0$ and $\phi=35$, there is a $62 \%$ increase in $\mathrm{F}_{\mathrm{w}}$ as $\mathrm{k}_{\mathrm{h}}$ increases 'from 0.2 to 0.3 . It is interesting to note that even a relatively moderate value of 0.2 for the horizontal acceleration leads to a value of 2.1 for $\mathrm{F}_{\mathrm{W}}$ : thus the wall mass required for stability is already more than double the static value.

The seismic amplification factor increases with increasing values of $\mathrm{k}_{\mathrm{v}}$ and decreasing values of $\phi$. This is evident from Figures 6 and 7 , but is shown more clearly in Figures 8 and 9. Note that these figures are drawn with scales which include very high values of $\mathrm{F}_{\mathrm{w}}$ to illustrate limiting trends. In practice, acceptable values of $F_{W}$ would be limited to values less than 5.0. W From Figure 8 it can be seen that, for instance, if $\mathrm{k}_{\mathrm{h}}=0.3$, then increasing the value of $\mathrm{k}_{\mathrm{v}}$ from 0 to 0.2 increases the seismic amplification factor from 3.5 to 5.0 , an increase of $43 \%$. However, for low values of $\mathrm{k}_{\mathrm{h}}$, vertical acceleration has only a relatively minor effect. Likewise the effects of changes in the soil friction angle (Figure 9) are fairly small for low values of $k_{h}$ and provided that $\phi$ is of the order of $30^{\circ}$. On the other hand, for less well-compacted soils and higher values of $\mathrm{k}_{\mathrm{h}}, \mathrm{F}_{\mathrm{w}}$ becomes very sensitive indeed to changes in $\phi$. Thus the importance of providing a well-compacted backfill is clearly demonstrated.

Figure 10 shows that the wall friction angle $\delta$ has very little effect on the seismic amplification factor. Figure 11, on the other hand, is more interesting. It shows the limits of the backfill slope i (the loci of these limits are shown as dashed lines), how the limits are affected by the soil strength $\phi$, and how the limits are approached: the curves of $F_{W}$ against $i$ have infinite slope when the limits are reached. It can be seen that well away from the limit loci the backfill slope angle has only a minor effect, but that as the limit is approached, the effect begins to grow rapidly. We may thus conclude that if the backfill slope is restricted to at least $5^{\circ}$ below the limit given by $\mathrm{Eq} .4$, its value has little effect on $F_{\mathrm{W}}$. It should be noted, though, that Eq. 4 is sensitive to the true value of $\phi$.

Figure 12 indicates that for wall slopes greater than $-10^{\circ}, \beta$ has little effect on $F_{W}$, but that the effect starts to become important as $\beta$ becomes increasingly negative. However, as we shall see later, negative batter angles are usually necessary in order to ensure that a wall will slide, if it moves, rather than tilt.

\section{STABILITY AGAINST TILTING}

Because Eq. I assumes the wall is in a critical state at which failure is just taking place, the horizontal acceleration coefficient $\mathrm{k}_{\mathrm{h}}$ should be regarded as the critical acceleration coefficient at which the wall will begin to move. If $\mathrm{k}$ is exceeded in an earthquake event, displacement of the wall will take place. If movement is going to occur, it is better that the wall should move by sliding outwards rather than by tilting. A condition for this may be expressed in terms of the position of the centre of pressure of the forces acting on the base of the wall. Consideration of the equilibrium of the forces acting on the wall (Figure 1) shows that in order that the wall should slide rather than overturn, it is necessary that the value of the distance $x_{0}$ from the inner toe of the wall to the point of action of the resultant force on the base of the wall should at least be equal to

$x_{0}=\frac{h[\cos (\beta+\delta)+\tan \beta \sin (\beta+\delta)]+C_{I E} F\left[k_{h} \bar{y}+\left(1-k_{v}\right) \bar{x}\right]}{\sin (\beta+\delta)+\left(1-k_{v}\right) C_{I E} F}$

where

$\mathrm{h}=$ height of resultant soil force (take $\mathrm{h}=\mathrm{H} / 2$ )

$\bar{x}, \bar{y}=$ coordinates of wall centre of gravity 

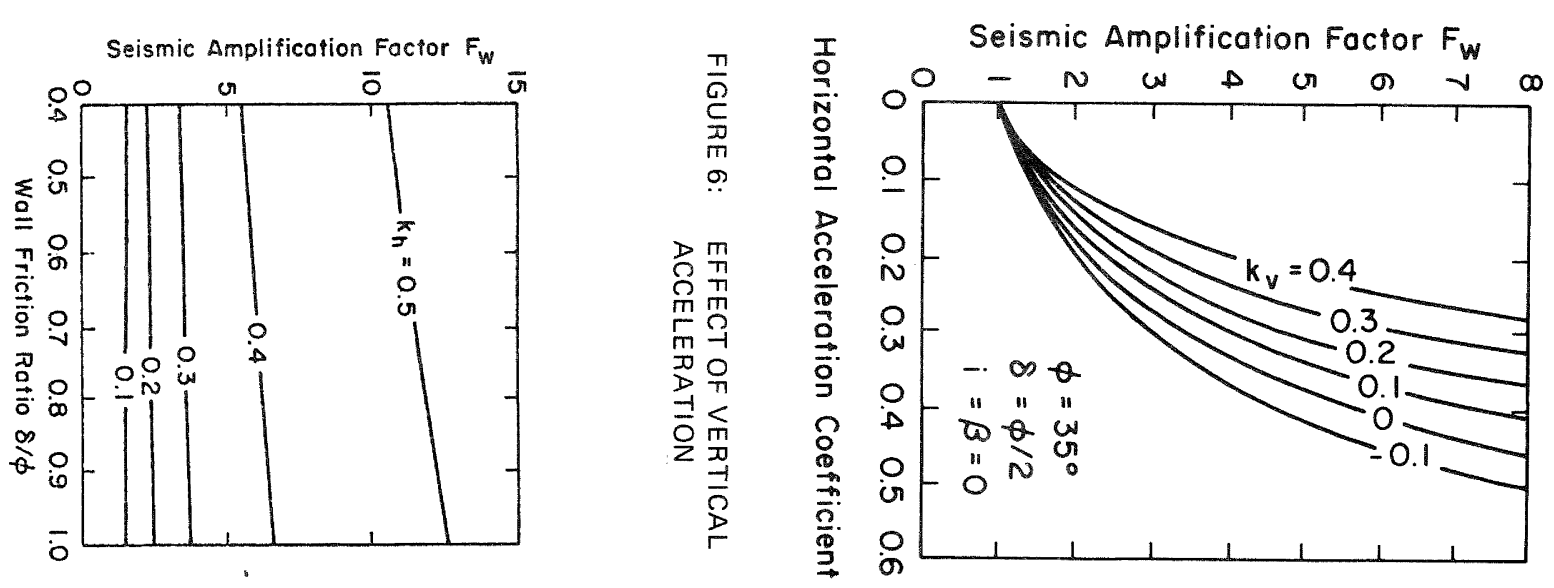

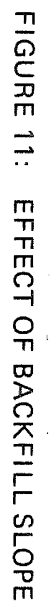
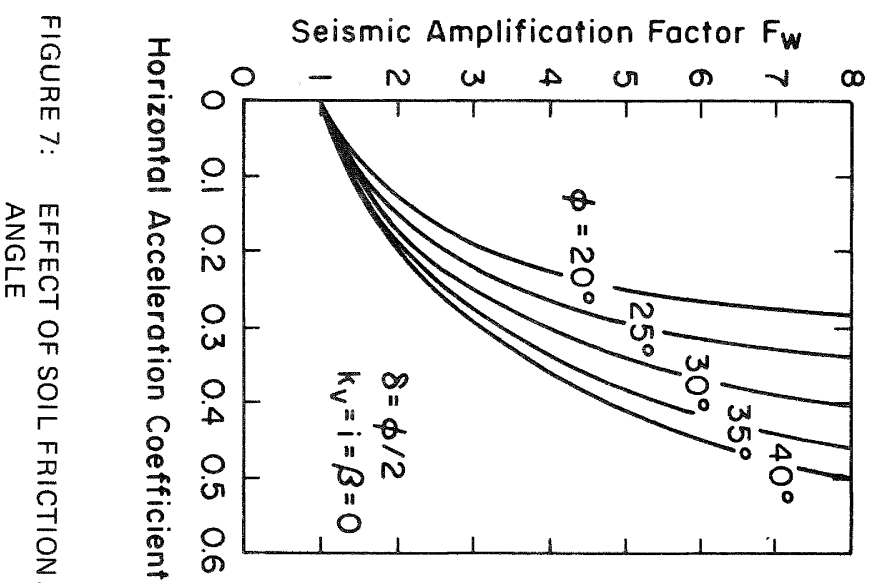

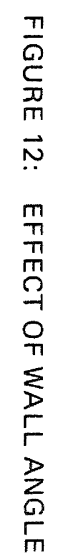
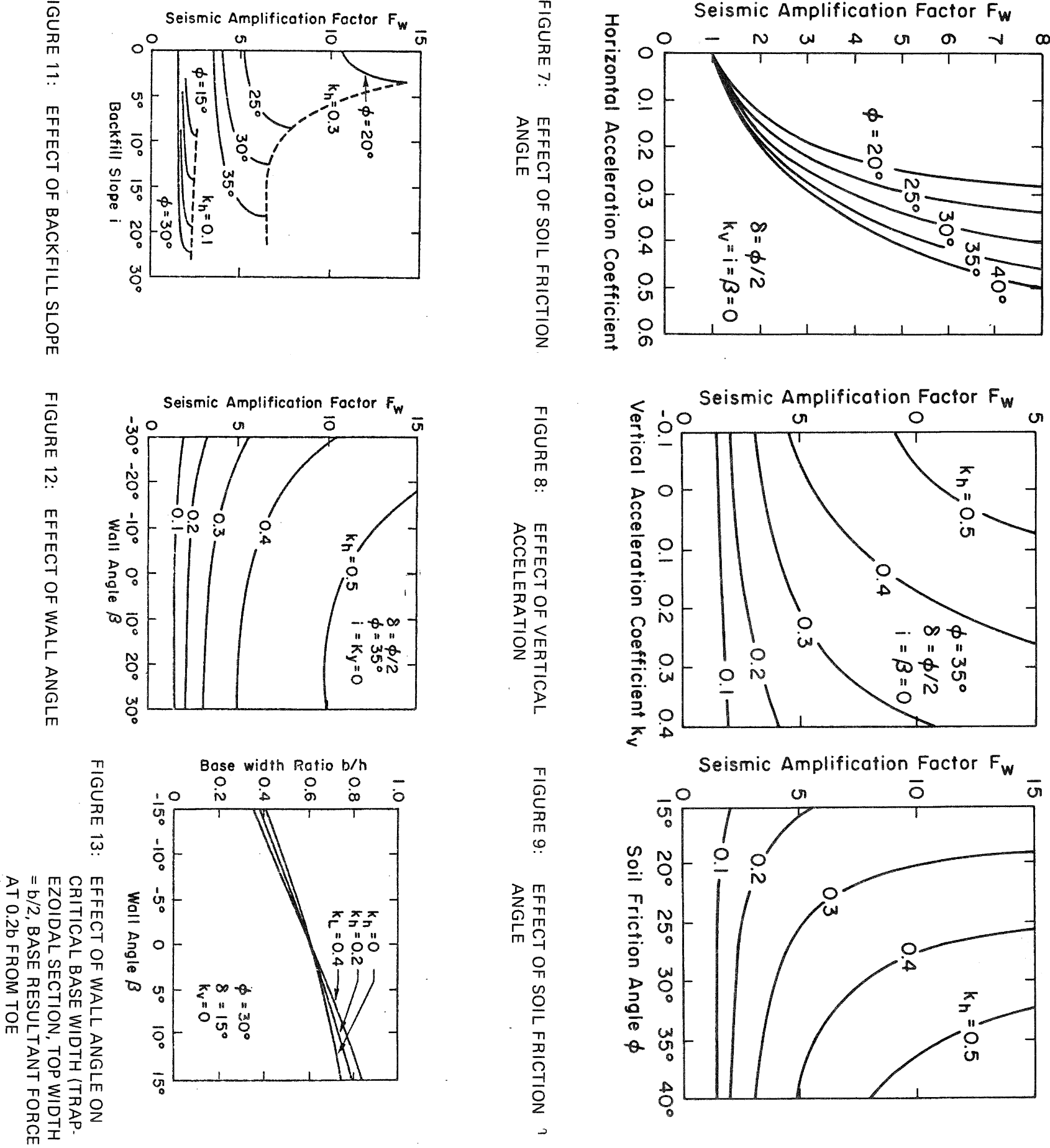

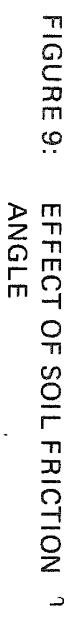

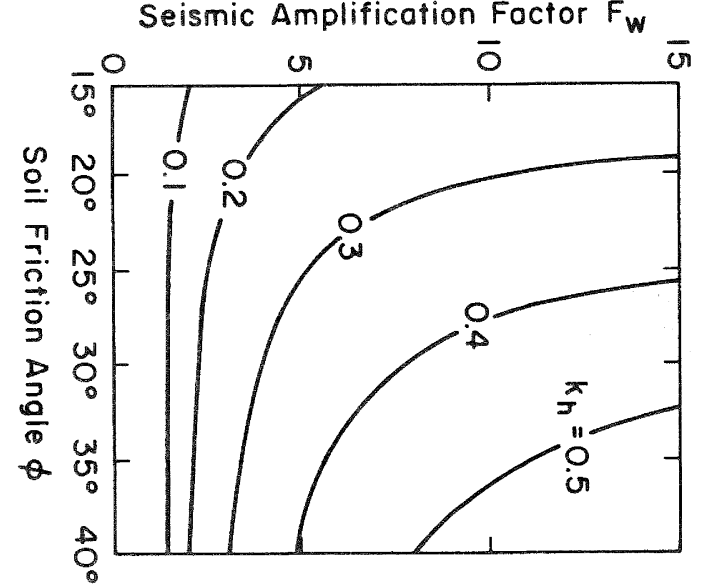


F

safety factor such that $\mathrm{FM}_{\mathrm{W}}=$ actual wall mass.

To illustrate the effect of this criterion, if $b$ is the base dimension of $a$ trapezoidal wall whose top has a width of $\mathrm{b} / 2$, Figure 13 shows that although the wall angle $\beta$ has a considerable effect on $b$, the base width is very little affected by the magnitude of $\mathrm{k}_{\mathrm{h}}$. Figure 14 gives a clearer illustration of the effect of the wall slope $\beta$, while Figure 15 shows the effect of different assumptions for the position of the resultant force on the base: $\mu=\left(b-x_{O}\right) / b$.

\section{DESIGN FOR DISPLACEMENT}

A difficulty arises that if the wall is designed using a reasonable value of acceleration coefficient, such as the coefficient C specified by NZS 4203:1976(5), then its mass will often need to be excessively great. An alternative procedure may be used to overcome this problem and produce a more economic design: the wall should be designed for a small predetermined displacement in an earthquake, rather than for no movement at all.

In order to develop such a procedure, it is first necessary to obtain an expression for the maximum displacement of a wall in a given earthquake.

Tests have shown that a gravity retaining wall fails in an incremental manner in an earthquake. For any earthquake record, the total relative displacement is finite, and is calculable by the Newmark sliding block method(2), developed originally for computing displacements of earth dams and embankmenis. It assumes a displacement pattern similar to that of a block resting on a plane rough horizontal surface subjected to an earthquake, with the block being free to move against frictional resistance in one direction only. Figure 16 shows how the relative displacement relates to the acceleration and velocity time histories of soil and wall. At a critical acceleration coefficient of $\mathrm{k}$, the wall is assumed to begin sliding: relative motion will continue until wall and soil velocities are equal. Figures 17 and 18, taken from an earlier publication (3), show the results of a computation of wall displacement for

$\mathrm{k}_{\mathrm{h}}=0.1$ for the $\mathrm{El}$ Centro $1940 \mathrm{~N}-\mathrm{S}$ record.

Newmark computed the maximum displacement responses for four earthquake records, and plotted the results after scaling the earthquakes to a common maximumacceleration and velocity. Franklin and Chang(1) repeated the analysis for a large number of both natural and synthetic records and added their results to the same plot. Upper bound envelopes for their results are shown in Figure 19. All records were scaled to a maximum acceleration coefficient $A$ of $0.5 \mathrm{~g}$ and a maximum velocity of $30 \mathrm{in} / \mathrm{sec}$. The maximum resistance coefficient $\mathrm{N}$ is the maximum acceleration coefficient sustainable by a sliding block before it slides: in the case of a wall, the maximum coefficient is of course $\mathrm{k}_{\mathrm{h}}$.

Figure 19 shows that the displacement envelopes for all the scaled records have roughly the same shape.

An approximation to the curves for relatively low displacements is given by the relation, expressed in any consistent set of units,

$D=0.087 \frac{\mathrm{V}^{2}}{\mathrm{Ag}} \quad\left(\frac{\mathrm{N}}{\mathrm{A}}\right)^{-4}$

where $\mathrm{D}$ is the total relative displacement of a wall subjected to an earthquake record whose maximum acceleration coefficient and velocity are $A$ and $V$. This is drawn as $a$ straight line on Figure 19. Note that as this expression has been derived from envelope curves, it will tend to overestimate $D$ for most earthquakes.

The proposed design procedure for gravity retaining walls involves choosing a desired value of maximum wall displacement D together with appropriate earthquake parameters, and using Eq. 20 to derive a value of $\mathrm{k}_{\mathrm{h}}$. for which the wall should be designed. In New Zealand, the seismic coefficients given by NZS 4203:1976(5) are based roughly on the 5\% damping response spectrum for the El Centro $1940 \mathrm{~N}-\mathrm{S}$ record. For this record, we can take the effective peak acceleration and velocity to be $0.32 \mathrm{~g}$ and $25 \mathrm{~cm} / \mathrm{sec}$ respectively. This leads to the relation

$\mathrm{k}_{\mathrm{h}}=\mathrm{G}^{-1 / 4}$

where $G$ has a value of 0.37 for zone $A$, where $D$ is expressed in millimeters. Values of $G$ for all New Zealand seismic zones are given in Table 1. Note that because of the nature of the straight-line approximation used, Eq. 21 should not be used for values of $D$ less than $30 \mathrm{~mm}$.

The design procedure is thus as follows.

1. Select a desired displacement D.

2. Compute $\mathrm{k}_{\mathrm{h}}$ from Eq. 21 .

3. Compute the required mass from Eq. 13.

4. Check that the wall will slide rather than tilt, from Eq. 19.

As an example, consider the design of a reinforced concrete retaining wall $3 \mathrm{~m}$ high with horizontal backfill. The soil properties are $\phi=33^{\circ}, \delta=20^{\circ}, \gamma_{0}=1600$ $\mathrm{kg} / \mathrm{m}^{3}$. Choose a wall slope $\beta=-5^{\circ}$, and take $\mathrm{k}_{\mathrm{V}}=0$. Assume the wall is to be built in Seismic Zone A, for which NZS 4203: 1976 gives $\mathrm{C}=0.15$

It would be inappropriate to use the code value of $C$ as not only is $C$ based on a response spectrum, but also the peak response has been considerably reduced as it is intended for use with ductile structures. In the present case, as the spectrum has been based on the El Centro $1940 \mathrm{~N}-\mathrm{S}$ record, we should base our computations, to ensure zero movement, on the maximum acceleration coefficient for that earthquake, which may be taken as 0.33 . Taking, then, a value of $\mathrm{k}_{\mathrm{h}}=0.33$ and multiplying by a safety factor of 1.5 (in practice a lower factor would be appropriate for dynamic effects), Eq. 13 leads to a required mass of $14,680 \mathrm{~kg} / \mathrm{m}$, or assuming the density of concrete is $2,400 \mathrm{~kg} / \mathrm{m}^{3}$, the wall will require an average thickness of $2.04 \mathrm{~m}$. This is too massive a wall by far. 
Let us now specify an allowable displacement of $100 \mathrm{~mm}$. Then from Eq. 2l, with G $=0.37$, we obtain $k_{h}=0.117$, and hence again using a factor of safety of 1.5 , the required mass would be $4920 \mathrm{~kg} / \mathrm{m}$, or an average thickness of $0.68 \mathrm{~m}$.

The equivalent average thickness for a purely static design would be $0.54 \mathrm{~m}$. There would thus be little gained in designing for a specified displacement in excess of $100 \mathrm{~mm}$. However, it should be noted that to prevent the occurrence of permanent displacement under the design earthquake the wall would require a safety factor of at least $2.04 / 0.54=3.8$.

Checking the condition that the wall will slide rather than tilt, for a wall of uniform thickness (which establishes $\bar{x}$ and $\bar{y}$ ), Eq. 19 gives $x_{0}=0.91$. Assuming the centre of pressure is at $0.8 \mathrm{~b}$ from the origin, we find that the toe must be extended such that the base width $\mathrm{b}$ must be at least $1.14 \mathrm{~m}$.

\section{CONCLUSIONS}

It is thus clear that a gravity retaining wall designed for any reasonable safety factor for static conditions alone will experience permanent displacements in a moderately severe earthquake: to prevent all movement, the static safety factor would need to be so high that the wall would be uneconomic. A gravity wall should therefore be detailed to allow some movement to take place, and it should be proportioned so that its deformation would be by sliding rather than tilting. If the wall is rigidly restrained, the soil forces acting on it will build up to high values.

However, movement of the wall, when it does occur, will be finite, and calculable. Thus a design process can be used in which the designer first specifies an allowable displacement. He can then use this to determine a design acceleration coefficient which will depend on the seismic zone in which he is working, and use this to design the wall. Wall inertia forces are important and must be taken into account.

Although the design mass of a wall is not generally sensitive to most of the geometrical and material parameters involved, there are some ranges where this is not true and care must be taken. In particular, even modest backfill angles can sometimes cause trouble, and the results are sensitive to low values of $\phi$ for the backfill. It should, of course, be remembered that the analysis is restricted to gravity retaining walls with an unsaturated cohesionless backfill.

\section{REFERENCES}

1. Franklin, A. G. and Chang, F. K., "Earthquake Resistance of Earth and Rockfill Dams: Report 5: Permanent Displacements of Earth Embankments by Newmark Sliding Block Analysis", Miscellaneous Paper S-71-17, Soils and Pavements Laboratory, U.S. Army Engineer Waterways Experiment Station, Vicksburg, IIiss., November 1977.

2. Newmark, N. M., "Effects of Earthquakes on Dams and Embankments", Geotechnique, Vol. 15, No. 2, pp. 139-160, 1965.
3. Richards, R. and Elms, D. G., Civil Engineering Research Report 77-10, Department of Civil Engineering, University of Canterbury, Christchurch, New Zealand, June 1977.

4. Seed, H. B. and Whitman, R. V., "Design of Earth Retaining Structures for Dynamic Loads", ASCE Specialty Conference - Lateral Stresses in the Ground and Design of Earth Retaining Structures, American Society of Civil Engineers, 1970, pp. 103-147.

5. Standards Association of New Zealand, "Code of Practice for General Structure Design and Design Loadings for Buildings", NZS 4203:1976, Standards Association of New Zealand, Wellington, 1976.

6. Wood, J. H., "Earthquake-Induced Soil Pressures on Structures", Report No. EERL 73-05, Earthquake Engineering. Research Lab. , California Institute of Technology, Pasadena, Calif., 1973.

7. Wood, J.H., "Earthquake-Induced Pressures on a Rigid Wall Structure" Bulletin of the New Zealand National Society for Earthquake Engineering, Vol. 8, No. 3, September 1975, pp. $175-186$.

\section{GLOSSARY OF TERMS}

= earthquake maximum acceleration coefficient

$\mathrm{b}=$ breadth of wall foot

$\mathrm{C}_{\mathrm{IE}} \quad=$ inertia coefficient

D = wall displacement

$\mathrm{E}_{\mathrm{AE}}, \mathrm{E}_{\mathrm{PE}}=$ active and passive soil forces

$\mathrm{F} \quad=$ safety factor

$\mathrm{F}_{\mathrm{W}} \quad=$ seismic amplification factor

g = gravitational acceleration

$\mathrm{H} \quad=$ wall height

h = height of resultant soil force

i = backfill slope

$\mathrm{k}_{\mathrm{h}}, \mathrm{k} \mathrm{v}=$ horizontal and vertical acceler-

* ation coefficients

$\mathrm{k}_{\mathrm{h}}^{*} \quad=$ critical acceleration coefficient

$\mathrm{M} \quad=$ mass of wall

$\mathrm{N}=$ maximum resistance coefficient

$\mathrm{V} \quad=$ earthquake peak velocity

$\bar{x}, \bar{y} \quad=$ coordinates of centre of gravity

$\mathrm{x}_{\mathrm{O}} \quad=$ cordinate of centre of base pressure

B. = wall slope

$\gamma=$ soil density

$\delta=$ soil/wall friction angle

$\theta \quad=$ inertia angle

$\phi \quad=$ soil friction angle

$\phi_{\mathrm{b}} \quad=$ wall base/soil friction angle.

This paper was presented at the South Pacific Regional Conference on Earthquake Engineering held in Wellington on 8,9 and 10 May, 1979. 
TABLE 1

DISPLACEMENT COEFFICIENTS

FOR NEW ZEALAND SEISMIC ZONES

\begin{tabular}{|c|c|}
\hline Seismic Zone & $\begin{array}{c}\text { Displacement Coefficient } \\
\text { G }\end{array}$ \\
\hline A & 0.37 \\
B & 0.31 \\
C & 0.25 \\
\hline
\end{tabular}
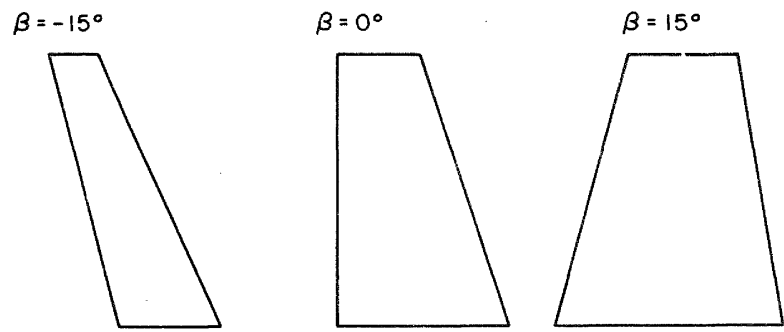

FIGURE 14: EFFECT OF WALL ANGLE ON CRITICAL BASE WIDTH
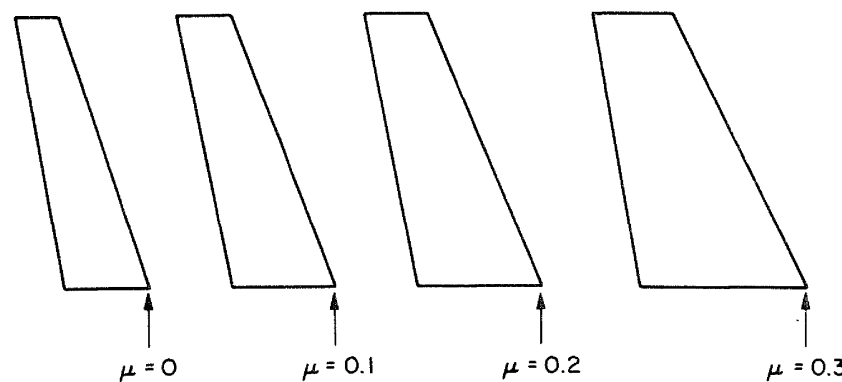

FIGURE 15: EFFECT OF BASE CENTRE OF PRESSURE ON CRITICAL BASE WIDTH

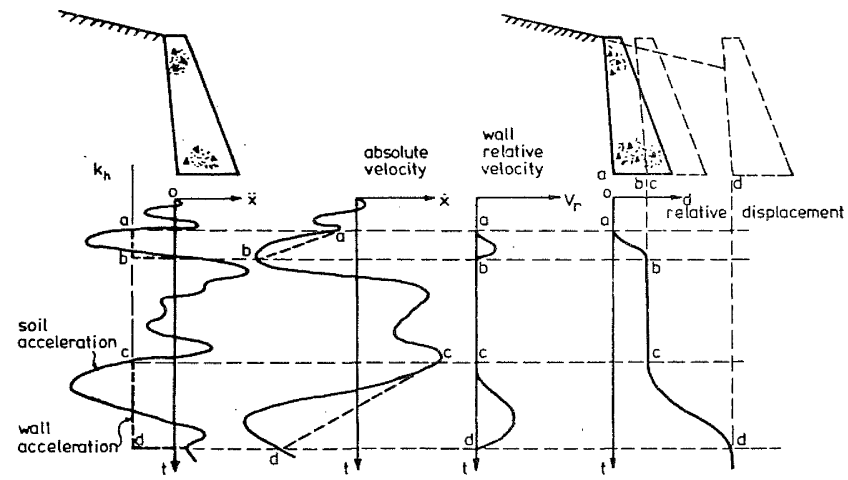

FIGURE 16: WALL DISPLACEMENT MECHANISM
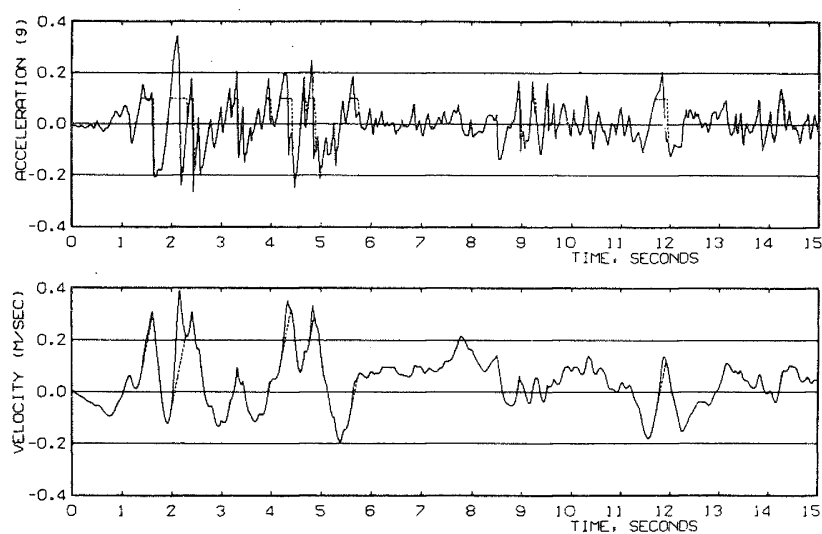

FIGURE 17: SOIL AND WALL ACCELERATIONS AND VELOCITIES -EL CENTRO $1940 \mathrm{~N}-\mathrm{S}$

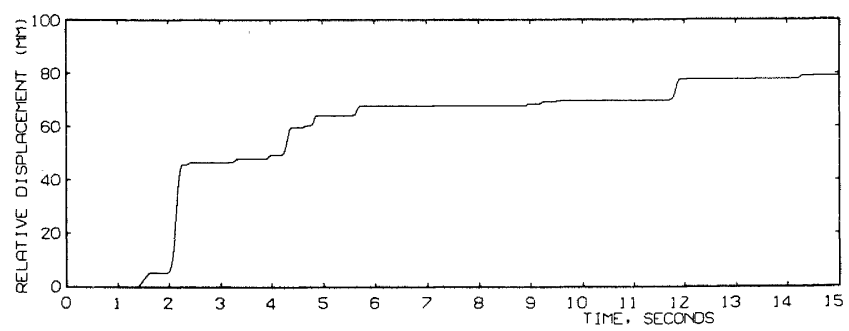

FIGURE 18: WALL DISPLACEMENT, EL CENTRO 1940 $\mathrm{N}-\mathrm{S}, \mathrm{k}_{\mathrm{H}}=0.1$

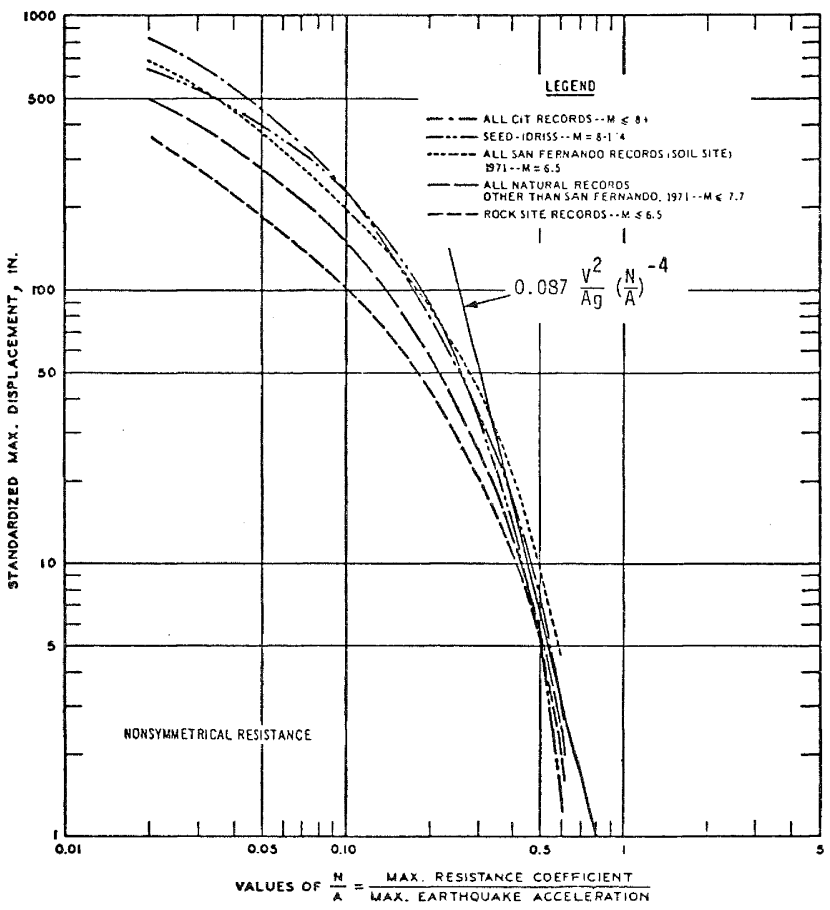

FIGURE 19: UPPER BOUND ENVELOPES AFTER FRANKLIN AND CHANG (1) 